\title{
Behavioral Implications of Budget Preparation: A Review and Future Research Context
}

\author{
Lutfa T Ferdous \\ La Trobe University \\ Bundoora Vic-3083 \\ Australia \\ Email: 1.ferdous@latrobe.edu.au
}

\begin{abstract}
This paper discusses the development of the behavioral implications of budget preparation and provides suggestions for future research on budgetary slack and its negative impact on budget preparation and performance evaluation and its influence on budget preparers and users. This paper extends future research by focusing on the proposed research question and research model including developed and developing economies. In doing so, this paper identifies research questions where evidence remains mixed and new directions in which there are research opportunities.
\end{abstract}

Keywords: Behavioral Implications, Budget Preparation, Budgetary Process.

\section{Introduction and Literature Review}

Budget is supposed to be effectively devised and well-coordinated short-term plan. Among other budget preparation process requires and improves coordination and goal congruence among organizational divisions and different hierarchical. It formalizes how information coming from various organizational levels is used and shared within an organization. Organizations have a choice to incorporate lower (Top-down budgeting) to higher (Bottom-up budgeting) degree of participation (from different hierarchical level) in the budgetary process. Two approaches are used in the budgeting process namely the top-down approach and bottom-up approach. The purpose of this paper is to open a question of whether an organization should use the top-down approach or bottom-up approach or a combination of both in the budgeting process. The problem will be analyzed based on procedural aspects involved in the budgeting process. The budgetary process is composed following steps in the sequence below:

- Issuance of budgetary guidelines by top management

- Development of initial budget proposal

- Budget committee meeting or Budget negotiation

- Approval to pair understandings from literature and interviews in each of the above steps to ensure that analytically accurate definitions of top-down and bottom-up orientation are operationalized.

Budget focused on behavior states that ongoing monitoring, periodic activities, and interactions with management and related personnel conveyed about by the firm's use of budgets to allocate resources and to measure and evaluate performance. Communication and coordination are central to the budget preparation process. Budgeting requires all participants to share reliable and accurate private information. Bottom-up budgeting (BU) relies upon managerial reporting while top-down budgeting (TU) is based on the principal's reporting. "Padding their budgets" (PB) managers may deliberately misreport private information if BU is applied while principal may falsify private information optimistically to fuel high efforts from managers for greater payoffs. From an economic perspective, total surplus is always maximized with bottom-up budgeting because the optimal bottom-up contract still sustains truth-telling with less surplus destruction than the optimal top-down arrangement (Heinle, Ross \& Saouma, 2014).

One of the targeted aims of participative budgeting is increased motivation among employees. This provides grounds that PB should be considered in terms of motivation framework. But a review of prior studies in PB has revealed a minimal use of the term "motivation." Moreover, the distinction is not available among various types of motivation. Differentiating motivation among intrinsic motivation, autonomous extrinsic motivation, and controlled extrinsic motivation is vital since it leads to different consequences. Two other factors have got importance in the study of PB's effect on motivation namely organizational commitment and environmental dynamics. 
First, organizational commitment is loyalty to the organization and has been defined as "the strength of an individual's identification with and involvement in a particular organization" (Porter et al., 1974). There are two subdivisions of organizational commitment namely continuance organizational commitment and affective commitment. Continuance commitment is derived from the high cost of departing from the organization while affective commitment is resultant of individual's emotional bond with an organization. Individuals having an affective commitment are probable to get intrinsic motivation while individuals having continuance commitment are required to be motivated extrinsically.

Second, environmental dynamism refers to the extent to which organizational factors are stable or volatile over time. An individual is having a natural propensity to face innovations and challenges to practice and test his capabilities usually tend to have intrinsic motivation. If the individual lacks such attributes, then the external drive is required to persuade time to do or participate in an activity. Results of various empirical studies revealed that the budgeting process could motivate participants either intrinsically or extrinsically (Conine, 2014). The relationship of specific type of motivation with performance is of great importance for management. The studies have shown that intrinsic motivation and autonomous extrinsic motivation are having a positive relationship with performance while controlled extrinsic motivation has a negative connection with performance. Moreover, organizational commitment is having a positive relationship with motivation while environmental dynamism is negatively associated with autonomous extrinsic motivation.

There are few open areas still work for budgeting. Studying PB within a general theoretical framework of motivation enables broader insights into the outcomes of budgeting exercise. Moreover, the discovery of the various motivational effects of different types of motivation triggers an examination of the great forms of motivation for PB (Wong, Guo, \& Lui, 2010). It also enables management to effectively handle the budgeting process to reap its benefits to the full potential.

\section{Proposed Research Questions for Future Research}

Annual targets are set through the budgetary process. The process has a strong connection with performance appraisal and incentive systems, therefore its impacts managerial perception of their exchange relationships. Different approaches to the budgetary process have varying impacts on the managerial understanding of social and exchange relationship with the company.

Social exchange theory assumes that human relationships are formed by practicing subjective cost-benefit analysis. It is related to the fields of sociology, psychology, and most importantly economics. It broadly identifies two types of exchanges namely economic exchange and social exchange.

Economic exchange is formally a transaction. It involves the inherent interests of participating parties. It is formal and subject to control systems. In contrast with economic exchange, social exchange is an informal relationship which involves transfer of non-economic socio-emotional resources such as respect, recognition and mutual support, etc.

Participative budgeting involves the participation of all the stakeholders in the budgeting process. Top-down orientation in budgeting process requires senior management to prepare a broad-based budget which is then sent to different divisions and departments of the organization that is necessary to develop a detailed budget with requisite allocations. Although top-down oriented budgets are usually incorporate a stronger strategic sense of private information of those who are below in organizational hierarchy is largely gets ignored. In contrast with top-down orientation, bottom-up orientation in budget setting enables the budget holder to participate in the budgeting process. Even though it renders ownership to budget holders but the plan may look strategically distant, and employees may misreport private information pessimistically to get less intensive budgets.

\subsection{Specification of Guidelines and Expected Targets through Issuance of Budgetary Guidelines by Top Management}

It is the first stage of the budgetary process. Under this stage, top-down orientation plays its role by issuing specific directives and expected target levels which are expected to increase the managerial perception of economic exchange with the organization. Since the budget guidelines and expected performance targets are imposed by top management with helps in emphasizing job fulfillment and understanding of economic exchange (Kramer \& Hartmann, 2014). On the other hand, bottom-up orientation in the first stage is not characterized by the issuance of guidelines or expected performance targets. Therefore bottom-up direction results in confusions and lack of perception of economic exchange. The following hypotheses can be tested in the context of Bottom-up (top-down)

H1: Bottom-up (top-down) orientation in the issuance of budgetary guidelines by top management decreases (increases) managerial perception of economic exchange with their company of employment. 


\subsection{Compliance with and Enforcement of Issued Guidelines in Preparation of Initial Budget by Subordinate Units}

Strong top-down orientation in preparation of initial budget results in a decrease of managerial perception of social exchange with their company of employment. There are numerous reasons behind it. First, the strong top-down orientation puts restrictions on subordinate managers during their budget planning process. Second, the limits are taken as constraints in freedom of expression. Moreover, a lack of tolerance for deviations and disregard to subordinate managers' view about target setting is treated as disrespectful. On the other hand, bottom-up orientation in initial budget preparation is assumed to increase the managerial perception of social exchange with the company of their employment.

H2: Bottom-up (top-down) orientation in the development of initial budget increases (decreases) managerial perception of social exchange with their company of employment.

\subsection{Rigidity in Budget Negotiation Process}

Strong top-down orientation in the budget negotiation process results in increased influence by upper-level units, i.e., lesser allowance is given to lower level units in the negotiation process. This results in a decrease in managerial perception of social exchange. On the other hand, bottom-up orientation in budget negotiation is assumed to increase the managerial understanding of social exchange with the company of their employment.

H3: Bottom-up (top-down) orientation in the negotiation of final budget increases (decreases) managerial perception of social exchange with their company of employment.

\subsection{The relationship between Managerial Perception of Social Exchange and Managerial Performance}

Based on prior research there is a strong relationship between managerial perception of social exchange and their performance. Increase in managerial perception of social exchange results in increased job satisfaction, organizational commitment, job involvement and self-efficacy and reduction on withdrawal behaviour (Rhoades and Eisenberger, 2002). These outcomes of increased perception of social exchange results in increased managerial performance.

H4: There is a direct relationship between managerial perception of social exchange with their company of employment and managerial performance.

\subsection{The relationship between an increase in Perception of Economic Exchange and the creation of budgetary slack}

Increase in perception of social exchange results in a decrease in the creation of budgetary slack due to the following reasons. Performance appraisal in an environment characterized by increased social exchange results in the little scope of managerial discretion. Moreover, there is increased emphasis on meeting profit targets through the meeting of challenging target leaving very little scope for budgetary slack.

H5: Managerial perception of economic exchange with their company of employment is inversely related to the creation of budgetary slack.

\section{Proposed Research Model}

Dependent and independent variables are used to develop hypotheses. Both the variables and hypotheses are integrated into a research model presented as follows:

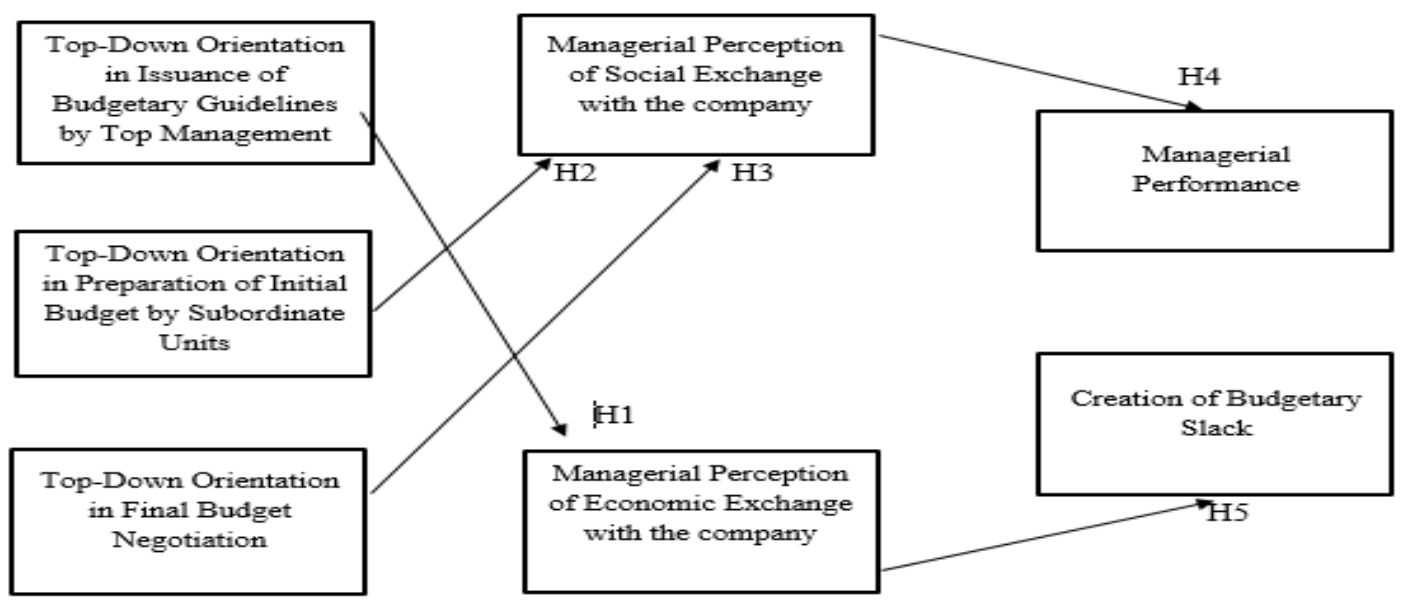




\section{Research Method}

To find out the validity of hypotheses development, data will be collected from large firms in 10 different sectors. Since sensitive information is involved in answering the questions, a field survey is used so that the information will not be biased and it might not influence the rest of the results and unbiased information will be obtained. Data will be collected from s survey questionnaire. The questionnaire is available in appendix-A. Hypotheses will be tested in the data analysis process.

\section{Conclusion}

To sum up, top-down and bottom-up orientations should be considered as absolute alternatives for the budgetary process; instead managers should remain alert about the implications of choosing a specific orientation in the context of a given budgetary stage. Among other benefits of proper budgeting selection of top-down and bottom-up orientation at the right stage of the budgetary process will help achievement of full and reliable disclosure of private information from all budget participants, intrinsic or autonomous extrinsic motivation of participants and reduction of budgetary slack.

\section{References}

Conine Jr, T. E. (2014). Estimating the probability of meeting financial commitments: A behavioral finance perspective based on business simulations. Global Business and Organizational Excellence, 33(2), 6-13.

Heinle, M. S., Ross, N., \& Saouma, R. E. (20134). A theory of participative budgeting. The Accounting Review, 89(3), 1025-1050.

Kramer, S., \& Hartmann, F. (2014). How top-down and bottom-up budgeting affect budget slack and performance through social and economic exchange. Abacus, 50(3), 314-340.

Merchant, K. A., \& Van der Stede, W. A. (2007). Management control systems: performance measurement, evaluation and incentives. Pearson Education.

Porter, L. W., Steers, R. M., Mowday, R. T., \& Boulian, P. V. (1974). Organizational commitment, job satisfaction, and turnover among psychiatric technicians. Journal of applied psychology, 59(5), 603.

Rhoades, L., \& Eisenberger, R. (2002). Perceived organizational support: a review of the literature. Journal of Applied Psychology, 87(4), 698

Wong-On-Wing, B., Guo, L., \& Lui, G. (2010). Intrinsic and extrinsic motivation and participation in budgeting: Antecedents and consequences. Behavioral Research in Accounting, 22(2), 133-153.

Note: It is important for managers to rank themselves for each of the above-mentioned managerial performance indicator

\section{Appendix A: Questionnaire}

Specification of Guidelines and Expected Targets through Issuance of Budgetary Guidelines by Top Management

- Top management is expecting achievable and relevant budget targets from functional units (1-5 i.e. low degree agreement-high degree agreement)

- The budget related expectations of top management (1: serve merely as guideline only)/ (5: are binding to functional units)

Compliance with and Enforcement of Issued Guidelines in Preparation of Initial Budget by Subordinate Units

- Functional units prepare initial budget (1: based on inputs from within the functional units) / (5: based on input from top management)

- During budget process, deviations from guidelines issued by top management are (1: highly probable)/ (5: not probable)

- Preparation of initial budget is bottlenecked by guidelines issued by top management (1-5 i.e. low degree agreement-high degree agreement)

Rigidity in Budget Negotiation Process

- Budgeting process involves (1: higher amount of time reserved for budget discussion and negotiation).

- Budgeting process involves (1: presentation of initial budget prepared by functional units that is then followed by discussion)/ (2: presentation of budget expectations of top management that is then followed by discussion) 
Relationship between Managerial Perception of Social Exchange and Managerial Performance (1: Strongly disagree; 5-Strongly agree)

- Managerial relationship s with is characterized by mutual trust.

- Managers work for optimization of organizational benefits in that they can depend on organization that it will take care of them in all the cases especially regarding budget making process.

- There is direct relationship of my contributions and roles in company with my longer run relationship with company.

- I recognize that my company has made sizeable investment in polishing my skills and personality,

- I recognize that my hard work is always followed by increased payoffs from organization.

- A lot of give and take is involved in relationship between me and my organization.

Relationship between increase in Perception of Economic Exchange and creation of budgetary slack (1: Strongly disagree; 5-Strongly agree)

- There is evident performance and reward relationship.

- There is economic relationship between me and my company i.e. I am fairly compensated for activities I do for my organization.

- My relationship with my company is characterized by clear specification of mutual obligations.

Creation of Budgetary Slack (1: Strongly disagree; 5-Strongly agree)

- I can be successful in getting easily attainable budgets approved.

- Budget targets are helpful in achieving greater efficiency in use of organizational resources.

- Budget targets encourage increased productivity in functional units.

- Budget targets are easily attainable.

- There is no inducement for me to improve efficiency due to budget targets.

Managerial performance (1: extraordinarily low performance; 5: extraordinarily high performance)

- Evaluation

- Supervision

- Staffing

- Overall performance

\section{Copyrights}

Copyright for this article is retained by the author(s), with first publication rights granted to the journal.

This is an open-access article distributed under the terms and conditions of the Creative Commons Attribution license (http://creativecommons.org/licenses/by/4.0/) 